\title{
Developing a predictive risk score for perioperative blood transfusion: a retrospective study in patients with oral and oropharyngeal squamous cell carcinoma undergoing free flap reconstruction surgery
}

\author{
Jun-Qi Su ${ }^{1 \#} \wedge$, Shang $\mathrm{Xie}^{2 \#}$, Zhi-Gang $\mathrm{Cai}^{2} \wedge$, Xiao-Ying Wang ${ }^{3}$ \\ ${ }^{1}$ Department of Clinical Laboratory, Peking University School and Hospital of Stomatology \& National Clinical Research Center for Oral Diseases \\ \& National Engineering Laboratory for Digital and Material Technology of Stomatology \& Beijing Key Laboratory of Digital Stomatology, Beijing, \\ China; ${ }^{2}$ Department of Oral and Maxillofacial Surgery, Peking University School and Hospital of Stomatology \& National Clinical Research Center \\ for Oral Diseases \& National Engineering Laboratory for Digital and Material Technology of Stomatology \& Beijing Key Laboratory of Digital \\ Stomatology, Beijing, China; ${ }^{3}$ Department of Medical Record, Peking University School and Hospital of Stomatology, Beijing, China \\ Contributions: (I) Conception and design: JQ Su, S Xie, ZG Cai; (II) Administrative support: ZG Cai; (III) Provision of study materials or patients: All \\ authors; (IV) Collection and assembly of data: JQ Su; (V) Data analysis and interpretation: JQ Su, S Xie; (VI) Manuscript writing: All authors; (VII) \\ Final approval of manuscript: All authors. \\ "These authors contributed equally to this work. \\ Correspondence to: Zhi-Gang Cai. Department of Oral and Maxillofacial Surgery, Peking University School and Hospital of Stomatology, 22 \\ Zhongguancun South Avenue, Haidian District, Beijing 100081, China. Email: c2013xs@163.com.
}

\begin{abstract}
Background: A simple and accurate scoring system to predict risk of blood transfusion in patients having surgical tumor resection with immediate free flap reconstruction primary surgery for oral and oropharyngeal squamous cell carcinoma (OOSCC) is lacking. Anticipating the blood transfusion requirements in patients with oral cancer is of great clinical importance. This research aimed to propose a valid model to predict transfusion requirements in patients undergoing surgery with free flap reconstruction for an OOSCC.

Methods: This retrospective study consisted of 385 patients who underwent oncologic surgery with immediate free flap reconstruction for locally advanced OOSCC from 2012 to 2019. The primary outcome measured was the exposure of patients to perioperative allogeneic blood transfusion. Based on a multivariate model of independent risk variables and their odds ratio, a blood transfusion risk score (TRS) was developed to predict the likelihood of the perioperative blood transfusion. The discriminatory accuracy of the model was evaluated using the area under the receiver operating characteristic (ROC) curve, and Youden index was used to identify the optimal cut-point.
\end{abstract}

Results: Logistic regression analyses identified lymph node status, preoperative hemoglobin $(\mathrm{Hb})$ levels, bone resection, osseous free tissue transfer, and operative duration were identified as independent predictors of blood transfusion. A TRS integrating these variables was separated into three categories. The TRS assessed the transfusion risk with good predictive ability, with an overall area under the ROC curve (AUC) was 0.826 . At the optimal cut-point of 5.5, the TRS had a sensitivity of $72.3 \%$ and a specificity of $78.2 \%$. The ROC analysis showed that patients with a TRS of 5.5 or more had a greater requirement for perioperative transfusion.

Conclusions: The use of the integer-based TRS allowed the identification of high-risk patients who may require perioperative transfusion undergoing tumor resection surgery for the treatment of OOSCC.

\footnotetext{
^ ORCID: Jun-Qi Su, 0000-0002-0548-2462; Zhi-Gang Cai, 0000-0001-7657-8843.
} 
Keywords: Blood transfusion; oral and oropharyngeal squamous cell carcinoma (OOSCC); free flap reconstruction; transfusion risk score (TRS); risk factor

Submitted Mar 12, 2021. Accepted for publication May 17, 2021.

doi: $10.21037 / \mathrm{atm}-21-1484$

View this article at: http://dx.doi.org/10.21037/atm-21-1484

\section{Introduction}

Surgery with radical tumor resection and free flap reconstruction is the most effective treatment for oral cancer. Although technological innovations and advances in the development of surgical instruments have lowered the risk of oral and maxillofacial tumor surgery, radical tumor resection and flap reconstruction are still regarded as highrisk surgeries. This is partly due to an especially high risk of substantial blood loss because of the complex structures involved and the extensive vascular distribution in the area. Efforts to prevent massive bleeding may be accompanied by appropriate transfusion in order to promote the safety of patients $(1,2)$. Blood transfusion is indispensable for ensuring oxygen transfer to hypoxic tissues and plasma volume expansion during bleeds. As such, perioperative blood transfusion is of great importance for oral and maxillofacial surgery supportive treatment.

However, allogeneic blood transfusions may have significant deleterious effects on the short- and longterm prognosis of patients undergoing surgery for head and neck cancer. Blood transfusions may be complicated by transfusion-transmitted diseases and other noninfectious transfusion-related risks (2,3). For example, the immunosuppressive effects of blood transfusions may promote tumor cell growth and postoperative tumor recurrence $(4,5)$. Furthermore, red blood cell transfusion is associated with prolonged hospitalization and inpatient readmission within 30 days $(6,7)$. Other studies have shown that allogeneic blood transfusions are significantly related to increased complications, tumor recurrence, and reduced survival rate in patients undergoing surgery with free flap reconstruction for head and neck cancer (8-14). Similarly, allogenic blood transfusion is associated with reduced survival rate and increased recurrence rates in patients having free-flap primary surgery for OOSCC (5). Additionally, transfusion volume is a perioperative factor for postoperative complications in patients undergoing oral and maxillofacial surgery (15). And perioperative allogeneic transfusion might confer a worse 5 -year overall survival in stage II-IV squamous cell carcinoma of the oral cavity, which is more than five-fold higher in the risk of death for patients transfused 3 or more units compared to those not transfused (4). Therefore, the transfusion risk of patients should be evaluated pre-surgery to minimize perioperative allogeneic blood transfusions to ensure patient safety. This will also help to optimize the distribution and allocation of blood resources.

This study was designed to identify significant variables and develop a scoring system to assess the risk of perioperative allogeneic blood transfusion in patients with OOSCC who underwent primary tumor resection followed by free flap reconstruction. Patient data were retrospectively collated from the Peking University School and Hospital of Stomatology over an 8 -year period. These findings can be used as a reliable reference to identify high-risk patients and reduce the possible adverse effects of blood transfusions by reducing allogeneic red blood cell transfusion and adopting appropriate blood protection strategies.

We present the following article in accordance with the STARD reporting checklist (available at http://dx.doi. org/10.21037/atm-21-1484)

\section{Methods}

\section{Data source and patients}

Patients with advanced OOSCC who underwent oncologic resection of the primary lesion followed by free flap reconstruction at the Department of Oral and Maxillofacial Surgery, Peking University School and Hospital of Stomatology, from January 2012 to June 2019 were enrolled in this study. Due to the retrospective nature of this study, the current study was granted an exemption by the Institutional Ethics Committee of Peking University School and Hospital of Stomatology. All procedure performed in the study were in accordance with the Declaration of Helsinki (as revised in 2013). Individual consent for this retrospective analysis was waived.

Selection criteria for patients included in the study are 
as follows: (I) primary OOSCC with clear typing diagnosed by biopsy; (II) clinical TNM stages III and IV; (III) surgery with free flap transfer reconstruction; (IV) no history of head and neck cancer; and (V) no distant metastatic disease. A total of 385 qualifying patients were selected for this study, including 101 patients with blood transfusions, and 284 patients without blood transfusions.

\section{Study variables and data collection}

Data were obtained from the Peking University Hospital of Stomatology Patient Information System, Oral and Maxillofacial Surgical Clinical Data Follow-up Database, and the hospital blood bank database. To identify preoperative and intraoperative predictors of perioperative blood transfusion in patients with OOSCC who underwent curative treatment with radical tumor resection and free flap reconstruction, the following factors between the blood transfusion group and the non-transfusion group were compared: (I) basic demographic data including age, gender, drinking status, smoking status, American Society of Anesthesiologists (ASA) score, and Charlson Comorbidity Index (CCI); (II) preoperative routine blood parameters including preoperative hemoglobin and preoperative hematocrit (HCT); (III) tumor factors including clinical primary tumor extension, clinical nodal status, and primary tumor localization; and (IV) surgical factors including surgical treatment scheme (bone resection, neck dissection range, and type of free flap), operative duration, and blood loss. Continuous variables were transformed into binary variables using the median as the cut-off point. Clinicopathological characteristics, routine preoperative blood parameters and outcome predictors were gathered to determine their association with blood transfusion. The following variables were assessed: age ( $>60 v s . \leq 60$ years), gender, clinical primary tumor extension (clinical T; T3-4 $v s$. T1-2), clinical nodal status (clinical $\mathrm{N} ; \mathrm{N}+v s . \mathrm{N} 0$ ), localization of primary tumor (tongue, floor of mouth, oropharynx, upper gum, lower gum, or buccal mucosa), drinking status (current, never or former), smoking status (current, never or former), CCI ( $\geq 1$ vs. 0), ASA score (I, II, or III), preoperative Hb level ( $\leq 133$ vs. $>133 \mathrm{~g} / \mathrm{L})$, preoperative HCT level $(\leq 0.39$ vs. $>0.39 \mathrm{~L} / \mathrm{L})$, bone resection (yes $v s$. no), neck dissection (bilateral vs. ipsilateral), type of free flap utilized (osseous vs. non-osseous), operative duration ( $>370 v s . \leq 370$ minutes) and blood loss (>300 vs. $\leq 300 \mathrm{~mL})$.

The preoperative and intraoperative clinical characteristics between transfusion and non-transfusion groups were compared by univariate analysis for an association with the need for perioperative allogenic transfusion, which was defined as the primary outcome variable. Variables that were related to transfusion in the univariable analysis with significant difference were eligible for entry into a multivariable analysis. The variables remained in the final model which were statistically associated with outcome measure were considered for the reliable predictors for perioperative blood transfusion in patients with OOSCC. Perioperative blood transfusion was defined as exposure to suspended red blood cells or suspended red blood cells with less leukocyte within 24 hours before surgery, during surgery, and within 24 hours after surgery. Transfusion with other blood products was not recorded.

Based on recommendations of American Association of Blood Banks (AABB), transfusion was implemented when the $\mathrm{Hb}$ level was lower than $70 \mathrm{~g} / \mathrm{L}$ in hospitalized hemodynamically stable patients and lower than $80 \mathrm{~g} / \mathrm{L}$ in patients with disturbed hemodynamics (16). According to current transfusion guidelines, the attending surgeon or anesthesiologist would make decisions on perioperative transfusions depends on individual patient factors such as patient age, clinical signs, severity of disease, comorbidities, hemoglobin concentration, etc.

\section{Statistical analyses}

The statistical analysis of data was conducted with Statistical Package for Social Science (SPSS) version 22.0 and statistical significance level was set at $\mathrm{P}<0.05$. Continuous and normally distributed data were presented using means with standard deviation (SD), whereas non-normal continuous variables using median with interquartile range. Absolute and relative frequencies were used to describe categorical variables. Univariate analysis using binary logistic regression was conducted to discover factors that were predictive of blood transfusion. A stepwise backward logistic regression analysis with $\mathrm{P}<0.05$ was applied to estimate a multivariate logistic regression model to select significant variables. The results are expressed as odds ratios (OR) with corresponding $95 \%$ confidence intervals (CI) for evaluating the strength of the correlations. A transfusion risk score (TRS) was developed using these independent variables, and the system's accuracy was assessed with area under the curve analysis using ROC curve. Significance was declared at $\mathrm{P}<0.05$. 


\section{Results}

\section{Patient characteristics}

The study cohort consisted of 385 patients with oral and oropharyngeal cancer who satisfied study inclusion criteria. The baseline clinical features of the patients are listed in Table 1. A total of 101 patients (26\%) received blood transfusions, with 28 patients (7\%) requiring 4 or more units \{median [interquartile range] $=2[2-4]$ units/patient\}. Of the 101 patients requiring blood transfusions, $35.6 \%$ (36 of 101) were transfused during the operation, 5.9\% (6 of 101) received blood within 24 hours before surgery, and $58.4 \%$ (59 of 101) received blood within 24 hours after surgery.

\section{Univariate analysis of blood transfusion in patients with OOSCC}

The results of univariate logistic regression analysis of risk factors for perioperative blood transfusion are given in Table 2. Gender $(\mathrm{P}=0.003)$, clinical $\mathrm{N}$ category $(\mathrm{P}=0.000)$, smoking status $(\mathrm{P}=0.020)$, $\mathrm{CCI}(\mathrm{P}=0.025)$, preoperative $\mathrm{Hb}$ level $(\mathrm{P}=0.000)$, preoperative HCT level $(\mathrm{P}=0.000)$, bone resection $(\mathrm{P}=0.000)$, type of free flap $(\mathrm{P}=0.001)$, operative duration $(\mathrm{P}=0.000)$, and intraoperative blood loss $(\mathrm{P}=0.000)$ were all significantly association with perioperative blood transfusion $(\mathrm{P}<0.05)$. Age, clinical primary tumor extension, primary tumor localization, drinking status, ASA score, and neck dissection had no significant impact on perioperative blood transfusion $(\mathrm{P}>0.05)$.

\section{Multivariate analysis of blood transfusion in patients with OOSCC}

Univariable analysis identified 10 variables significantly associated with increasing risk of exposure to perioperative transfusion (Table 2). These factors were then used in the multivariable analysis using stepwise backward logistic regression analysis with a $\mathrm{P}$ value border of 0.05 . Intraoperative hemorrhage was not considered due to the unpredictability of the preoperative situation. According to the multivariate analysis, the following 5 independent factors remained significantly related to an elevated risk of perioperative transfusion $(\mathrm{P}<0.05$, Table 2), namely, clinical nodal status $\geq 1(\mathrm{OR}=3.16 ; 95 \% \mathrm{CI}=1.8$ to $5.6 ; \mathrm{P}=0.000)$, preoperative $\mathrm{Hb}$ level $\leq 133 \mathrm{~g} / \mathrm{L}$ (OR $=4.60 ; 95 \% \mathrm{CI}=1.6$ to
Table 1 Patient demographics and clinical characteristics

\begin{tabular}{|c|c|}
\hline Characteristics & Patients, N [\%] \\
\hline Total No. of patients & 385 \\
\hline Age (years), mean $\pm \mathrm{SD}$ & $57.9 \pm 12.7$ \\
\hline \multicolumn{2}{|l|}{ Gender } \\
\hline Male & $238[62]$ \\
\hline Female & $147[38]$ \\
\hline \multicolumn{2}{|l|}{ Clinical TNM stage } \\
\hline III & 132 [34] \\
\hline IV & $253[66]$ \\
\hline \multicolumn{2}{|l|}{ Tumor localization } \\
\hline Tongue & 80 [21] \\
\hline Floor of mouth & $64[16]$ \\
\hline Oropharynx & $41[11]$ \\
\hline Upper gum & $53[14]$ \\
\hline Lower gum & 85 [22] \\
\hline Buccal mucosa & $62[16]$ \\
\hline \multicolumn{2}{|l|}{ Drinking status } \\
\hline Current & $120[31]$ \\
\hline Never or former & 265 [69] \\
\hline \multicolumn{2}{|l|}{ Smoking status } \\
\hline Current & $164[43]$ \\
\hline Never or former & $221[57]$ \\
\hline \multicolumn{2}{|l|}{ Charlson score } \\
\hline 0 & $298[77]$ \\
\hline 1 & $22[6]$ \\
\hline 2 & $31[8]$ \\
\hline 3 & $22[6]$ \\
\hline 4 & 9 [2] \\
\hline 5 & $3[1]$ \\
\hline \multicolumn{2}{|l|}{ ASA score } \\
\hline I & $73[19]$ \\
\hline$\|$ & 277 [72] \\
\hline III & 35 [9] \\
\hline Preoperative hemoglobin (g/dL), mean $\pm \mathrm{SD}$ & $130.1 \pm 20.6$ \\
\hline Hematocrit (L/L), mean $\pm S D$ & $0.39 \pm 0.06$ \\
\hline
\end{tabular}

Table 1 (continued) 
Table 1 (continued)

\begin{tabular}{|c|c|}
\hline Characteristics & Patients, N [\%] \\
\hline \multicolumn{2}{|l|}{ Bone resection } \\
\hline Yes & $286[74]$ \\
\hline No & 99 [26] \\
\hline \multicolumn{2}{|l|}{ Neck dissection } \\
\hline Ipsilateral & $279[72]$ \\
\hline Bilateral & $106[28]$ \\
\hline \multicolumn{2}{|l|}{ Free flap } \\
\hline Fibular osteocutaneous & $121[31]$ \\
\hline Lateral thigh & $113[29]$ \\
\hline Radial forearm & $78[20]$ \\
\hline Pectoralis major & $26[7]$ \\
\hline Submental island & $33[9]$ \\
\hline Iliac & 6 [2] \\
\hline Rectus abdominis & $3[1]$ \\
\hline Other & $5[1]$ \\
\hline Operative duration (minutes), mean \pm SD & $379 \pm 111$ \\
\hline Blood loss $(\mathrm{mL})$, mean \pm SD & $359 \pm 182$ \\
\hline \multicolumn{2}{|l|}{ Blood transfusion } \\
\hline No & $284[74]$ \\
\hline Yes & $101[26]$ \\
\hline $1-3$ units & $73[19]$ \\
\hline$>3$ units & $28[7]$ \\
\hline
\end{tabular}

SD, standard deviation; TNM, tumor node metastasis; ASA, American Society of Anesthesiologists.

13.2; $\mathrm{P}=0.005)$, bone resection $(\mathrm{OR}=2.78 ; 95 \% \mathrm{CI}=1.3$ to 6.0; $\mathrm{P}=0.009)$, osseous free flap ( $\mathrm{OR}=1.80,95 \% \mathrm{CI}=1.0$ to 3.2 ; $\mathrm{P}=0.049)$, and operative duration $>370$ minutes $(\mathrm{OR}=2.68$; $95 \% \mathrm{CI}=1.5$ to $4.8 ; \mathrm{P}=0.001)$.

\section{Development of the prediction model}

A TRS was developed using the variables identified statistically significant in the final multivariable logistic regression model. The regression coefficients for each predictors were converted to an integer-based weighted point system considered for easier clinical use. Each predictor was given a score from 0 to 3 respectively based on the beta coefficient (Table 3) and the sum of the integer scores was calculated for every patient (ranging from 0 to 10 points) to estimate blood transfusion risk. As a reference, clinical nodal status $=0$, preoperative $\mathrm{Hb}$ level $>133 \mathrm{~g} / \mathrm{L}$, surgery without bone resection, soft-tissue flap reconstruction, and operative duration $\leq 370$ minutes were assigned a score of zero. Preoperative Hb level $\leq 133 \mathrm{~g} / \mathrm{L}$ had the greatest association $(\beta=1.526)$ with increased risk of requiring blood transfusion, followed by clinical nodal status $\geq 1 \quad(\beta=1.150)$, bone resection ( $\beta=1.024)$, operative duration $>370$ minutes $(\beta=0.986)$, and osseous free flap $(\beta=0.586)$. Osseous free flap showed the lowest regression coefficients $(0.586)$ and was assigned a score of 1 . Clinical nodal status $\geq 1$, bone resection, and operative duration $>370$ minutes shared similar and relatively moderate regression coefficients $(1.15,1.024$, and 0.986 , respectively) and were assigned a score of 2. Preoperative Hb level $\leq 133 \mathrm{~g} / \mathrm{L}$ (regression coefficient $=1.526$ ) was assigned a score of 3 . As the goal was to produce a simple-to-use integer risk score, the total scores (ranges varying from 0 to 10 points) were divided into 3 categories (scores $0-3$ were considered low, scores 4-5 were moderate, and scores 6-10 were considered the high-risk group). Therefore, patients with a higher score tended to show a greater need for perioperative blood transfusion. The proportion of patients who required blood transfusion according to the TRS is shown in Table 4. Rates for transfusion were $3.4 \%, 17.9 \%$, and $54.1 \%$ for the low-risk, medium-risk and high-risk groups, respectively. The emerging scoring model clearly distinguished among patients at different levels of risk associated with exposure to blood transfusion and the prediction model exhibited a strong diagnosis ability (AUC $=0.826,95 \% \mathrm{CI}=0.781$ to $0.871, \mathrm{P}<0.05$ ) based on the multivariate model (Figure 1). Additionally, Youden index was calculated to obtain the optimal cutoff point with the best sensitivity-specificity balance. The ROC analysis showed that patients with a risk score of 5.5 or more had a greater requirement for perioperative transfusion, with sensitivity of $72.3 \%(73 / 101)$ and specificity of $78.2 \%$ (222/284; Figure 1$)$. These analyses demonstrated that the model has good predictive ability for perioperative transfusion in patients with OOSCC.

\section{Discussion}

Currently, the attending surgeon or anesthesiologist makes decision on the blood transfusions depends on their previous professional experience and individual patient factors. However, personal clinical experience has its limitations, and it is difficult to standardize. In this study, a 
Table 2 Univariate and multivariate logistic regression analyses of predictive factors for perioperative blood transfusion

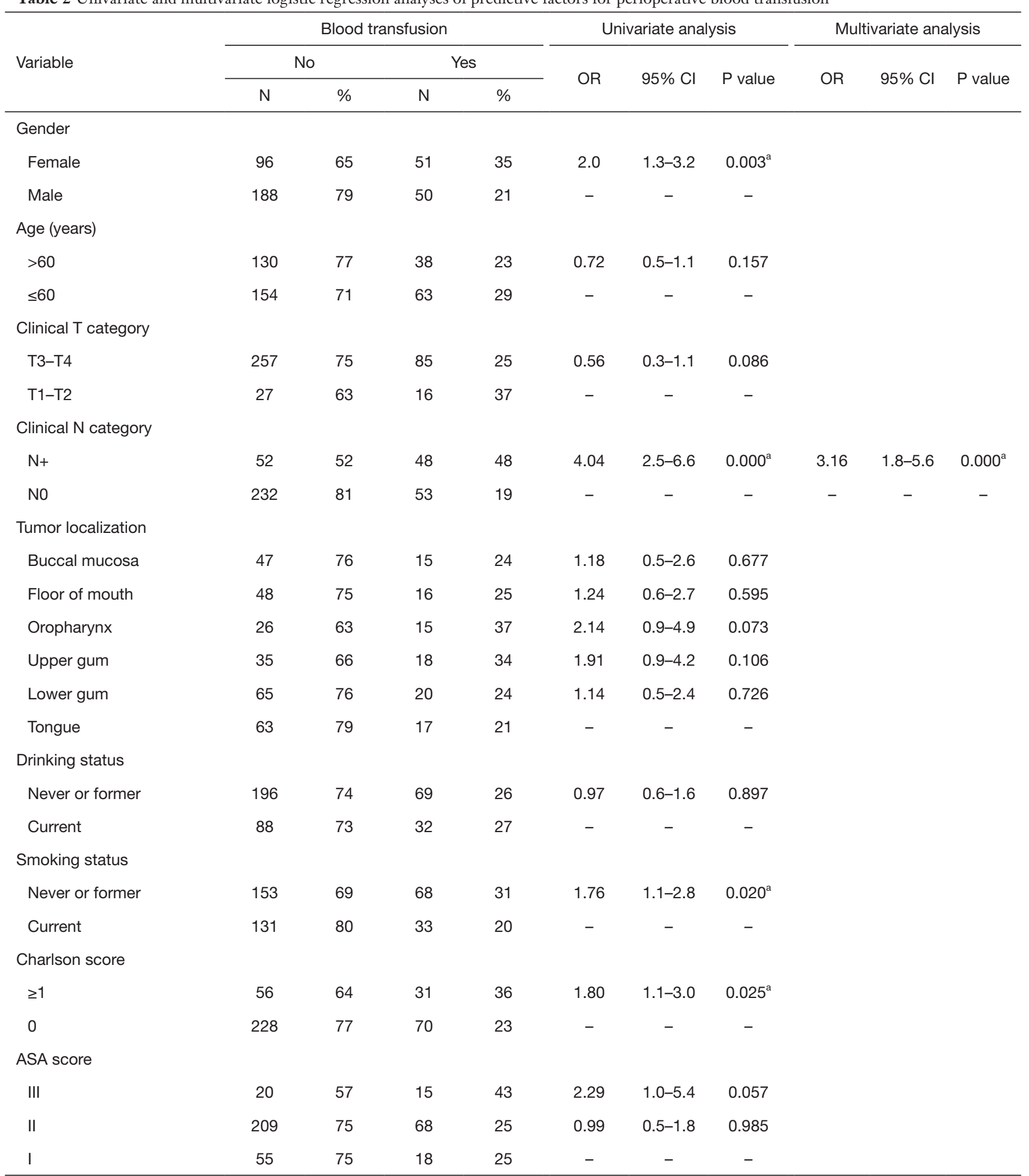

Table 2 (continued) 
Table 2 (continued)

\begin{tabular}{|c|c|c|c|c|c|c|c|c|c|c|}
\hline \multirow{2}{*}{ Variable } & \multicolumn{4}{|c|}{ Blood transfusion } & \multicolumn{3}{|c|}{ Univariate analysis } & \multicolumn{3}{|c|}{ Multivariate analysis } \\
\hline & $\mathrm{N}$ & $\%$ & $\mathrm{~N}$ & $\%$ & OR & $95 \% \mathrm{Cl}$ & $P$ value & OR & $95 \% \mathrm{Cl}$ & $P$ value \\
\hline \multicolumn{11}{|c|}{ Preoperative hemoglobin (g/L) } \\
\hline$\leq 133$ & 111 & 57 & 83 & 43 & 7.19 & $4.1-12.6$ & $0.000^{\mathrm{a}}$ & 4.60 & $1.6-13.2$ & $0.005^{a}$ \\
\hline \multicolumn{11}{|l|}{ Hematocrit (L/L) } \\
\hline$\leq 0.39$ & 115 & 58 & 82 & 42 & 6.34 & $3.7-11.0$ & $0.000^{\mathrm{a}}$ & & & \\
\hline$>0.39$ & 169 & 90 & 19 & 10 & - & - & - & & & \\
\hline \multicolumn{11}{|l|}{ Bone resection } \\
\hline \multicolumn{11}{|l|}{ Neck dissection } \\
\hline Bilateral & 78 & 74 & 28 & 26 & 1.01 & $0.6-1.7$ & 0.960 & & & \\
\hline Ipsilateral & 206 & 74 & 73 & 26 & - & - & - & & & \\
\hline \multicolumn{11}{|l|}{$\begin{array}{l}\text { Type of free-flap } \\
\text { reconstruction }\end{array}$} \\
\hline Osseous & 73 & 62 & 44 & 38 & 2.23 & $1.4-3.6$ & $0.001^{a}$ & 1.80 & $1.0-3.2$ & $0.049^{a}$ \\
\hline Non-osseous & 211 & 79 & 57 & 21 & - & - & - & - & - & - \\
\hline \multicolumn{11}{|c|}{ Operative duration (minutes) } \\
\hline
\end{tabular}

${ }^{\mathrm{a}}$, these figures indicate statistical significance. Cl, confidence interval; OR, odds ratio; ASA, American Society of Anesthesiologists.

simple and accurate scoring system was developed to predict and manage the risk of blood transfusion for patients with OOSCC undergoing surgery with primary free flap reconstruction.

In the field of oral and maxillofacial surgery, blood conservation strategies such as preoperative autologous blood donation, acute perioperative normovolemic hemodilution, and the monitoring of outcome measures of transfusion by the attending physician may avoid or reduce the requirement of allogeneic blood transfusion. Different blood conservation strategies have their own merits and drawbacks. However, none of these strategies are widely regarded as the optimal blood conservation method $(8,17-21)$. Therefore, it would be advantageous to identify the preoperative and predictable intraoperative variables predicting the need for allogenic transfusion in patients with OOSCC undergoing surgery with radical tumor resection and free flap reconstruction.

A full evaluation of patient risks and reasonable blood preparation prior to surgery are essential to ensure the safety of the patient. This study developed a TRS to accurately predict transfusion requirements in patients undergoing curative surgery for OOSCC. Five perioperative factors, namely, clinical $\mathrm{N}$ category, preoperative hemoglobin levels, 
Table 3 Development of the predictive scores based on logistic regression analyses

\begin{tabular}{|c|c|c|c|c|}
\hline Characteristic & Integer risk score & Regression coefficient $\beta$ & Odds ratio $(\beta)$ & $P$ value \\
\hline $\mathrm{N}+$ & 2 & 1.150 & 3.158 & 0.000 \\
\hline NO & 0 & & & \\
\hline \multicolumn{5}{|c|}{ Preoperative hemoglobin (g/L) } \\
\hline$>133$ & 0 & & & \\
\hline \multicolumn{5}{|l|}{ Bone resection } \\
\hline Yes & 2 & 1.024 & 2.784 & 0.009 \\
\hline No & 0 & & & \\
\hline \multicolumn{5}{|c|}{ Type of free-flap reconstruction } \\
\hline Non-osseous & 0 & & & \\
\hline \multicolumn{5}{|c|}{ Operative duration (minutes) } \\
\hline$>370$ & 2 & 0.986 & 2.681 & 0.001 \\
\hline$\leq 370$ & 0 & & & \\
\hline
\end{tabular}

Table 4 Frequency of blood transfusion by transfusion risk score

\begin{tabular}{lcccc}
\hline TRS groups & Total score & No. of patients $(\%)$ & No. of patients transfused & Frequency of blood transfusion \\
\hline Low risk group & $0-3$ & $116(30.1)$ & 4 & 3.4 \\
Moderate risk group & $4-5$ & $134(34.8)$ & 24 & 17.9 \\
High risk group & $6-10$ & $135(35.1)$ & 73 & 54.1 \\
\hline
\end{tabular}

TRS, transfusion risk score.

bone resection, osseous free flap, and operative duration, were identified as the independent risk factor for blood transfusion.

As the value of regression coefficients for blood transfusion varied somewhat for independent variables, the TRS for predicting perioperative blood transfusion was stratified into low-, moderate-, and high-risk patients. The area under the ROC curve indicated that the point scoring system showed good discrimination and predictive value, indicating the model was simple to use and accurate.

Overall, the scoring system developed in this report could accurately assess the risk and necessity of blood transfusion for patients. This may be an important measure in clinical diagnosis and treatment. First, the TRS can identify high-risk patients for blood transfusions in advance, thereby allowing the optimization and allocation of blood resources. Use of the TRS could provide effective auxiliary guidance and scientific basis for clinical decision-making regarding blood transfusions. Second, the TRS will allow pre-surgical briefing of patients regarding the probability that they will need blood transfusions and the potential risks. Third, it will allow high-risk patients to complete a comprehensive transfusion-associated examination presurgery and be cross-matched for packed red blood cells (PRBCs) prior to surgery. Finally, improving the cost effectiveness of the autologous blood donation programme could lead to substantial savings and maximize the benefits of such a system. High-risk patients should be encouraged to participate in autologous blood donation programme, and conversely, autologous blood donation should not be encouraged in low-risk patients, thus reducing or avoiding costs relating to over collection of blood. 


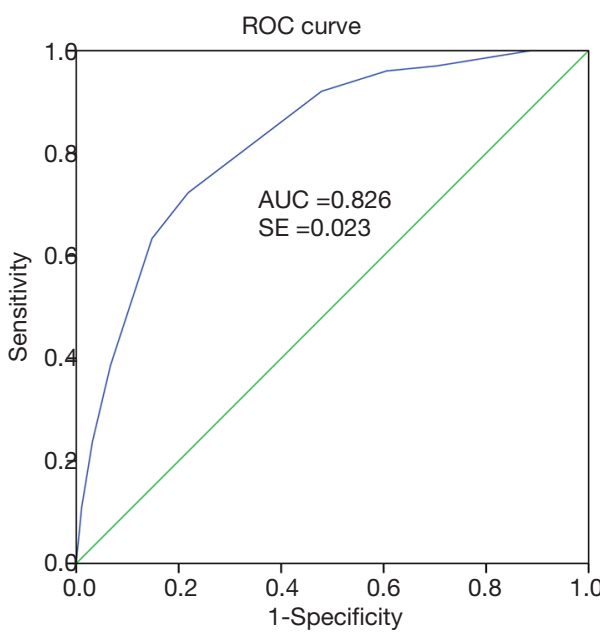

Figure 1 ROC curve analysis of the preoperative risk factors for predicting transfusion requirement $(\mathrm{AUC}=0.826, \mathrm{P}<0.05)$. ROC, Receiver operating characteristic; AUC, area under the curve; SE, standard error.

To date, there are few studies in the literature examining the predictors of blood transfusion in head and neck cancer surgery. Furthermore, and there is no consensus on this issue due to the different research populations and blood transfusion standards. This current study was based on 385 patients who underwent curative surgery for OOSCC in the Peking University Hospital of Stomatology over the past eight years. Clinical N category $\geq 1$, preoperative $\mathrm{Hb}$ levels $<133 \mathrm{~g} / \mathrm{L}$, bone resection, osseous free tissue transfer, and operative duration $>370$ minutes were independently associated with increased blood transfusion requirements. Our current study showed preoperative $\mathrm{Hb}$ levels $<133 \mathrm{~g} / \mathrm{L}$ is an independent risk factor for perioperative blood transfusion, which revealed a significant difference in the distribution of hemoglobin between the blood transfusion and non-transfusion group. This agrees with previous reports showing that preoperative $\mathrm{Hb}$ levels $<120 \mathrm{~g} / \mathrm{L}$ is an independent risk factor for intraoperative blood transfusion (22). In general, low preoperative hemoglobin levels were associated with a high likelihood of intraoperative blood transfusion.

Multivariate analysis showed that bone resection and osseous free flap reconstruction were both related to higher transfusion requirements. This may reflect the significant blood loss that is often associated with major resection of bone and the potential technical difficulties of complex maxillofacial surgical procedures. Moreover, reconstruction with osseous free flap may be secondary to additional blood loss from the free-flap harvest. This is consistent with the findings of Perisanidis et al. demonstrating that bone resection and osseous free flap transplantation are related factors for allogeneic blood transfusion during reconstruction of free-flap in patients with OOSCC (22). Adoption of methods such as hypotension anesthetics and the use of meticulous surgical techniques may minimize blood loss.

Some investigations have indicated that low hemoglobin levels and clinical $\mathrm{N}$ category $\geq 2$ are relevant factors contributing to perioperative blood transfusion in patients with head and neck cancer (23). This current study found that clinical $\mathrm{N}$ category $\geq 1$ was a risk factor for perioperative transfusion. The clinical $\mathrm{N}$ category is based on the involvement of regional lymph nodes. A greater spread to lymph nodes results in an expansion of the surgical scope and trauma area in patients with advanced tumors, thus potentially increasing perioperative hemorrhage and transfusion requirements. Multivariate logistic regression analysis in this study also demonstrated that the operative duration is a relevant factor for blood transfusions. Therefore, standardizing surgical operations, improving technical skills, and minimizing blood loss are conducive to avoiding or reducing blood transfusions.

While this study used restricted criteria to control bias, but there are certain limitations. First, our model was evaluated in limited single-institution retrospective study and further multi-institution studies with a larger sample sizes are necessary to improve the evidence-based conclusions. Second, the indicators of perioperative blood transfusion could be impacted by many factors, depending on the decision of both the chief surgeon and anesthetist, resulting in potential bias. Increasing sample size and applying a better matching method may rule out this bias. Third, only TNM stages III and IV were used in the inclusion criteria and this may lead to potential selection bias which may interfere with whether clinical $\mathrm{T}$ categories are associated with an increased risk of blood transfusion. Finally, future prospective randomized clinical trials are warranted to further confirm the conclusions of this study.

In summary, clinical $\mathrm{N}$ category, preoperative anemia, bone resection, osseous free flap reconstruction, and operative duration are the main determinants of whether a patient requires blood transfusions. The transfusion risk assessment scores developed in this report can be used to stratify high-, moderate-, and low-risk patients, and provide essential information for clinical decision-making. Clinicians should conduct a comprehensive analysis of the related factors in considering blood transfusions for patients 
with OOSCC. The ability to identify patients at high risk of transfusion is critical to optimize blood conservation strategies to avoid potential harmful effects caused by transfusions, improve outcomes, minimize wastage of blood products, and decrease the economic burden. In addition, the scoring system developed in this study could accurately predict the likelihood of transfusions and warrants further research and confirmation. The use of the TRS in patients with OOSCC who underwent surgical procedure requiring free-flap reconstruction may alter transfusion practices. For example, high-risk patients may be encouraged to participate in preoperative autologous blood donation programme, or be cross-matched for PRBCs before surgery, thereby contributing to more reasonable, effective, and personalized blood transfusion management.

\section{Acknowledgments}

Funding: This research was funded by the National Natural Science Foundation of China [Grant numbers 82002878 and 81870781] and the Peking University Hospital of Stomatology Young Foundation [Grant number YS020219].

\section{Footnote}

Reporting Checklist: The authors have completed the STARD reporting checklist. Available at http://dx.doi.org/10.21037/ atm-21-1484

Data Sharing Statement: Available at http://dx.doi. org/10.21037/atm-21-1484

Conflicts of Interest: All authors have completed the ICMJE uniform disclosure form (available at http://dx.doi. org/10.21037/atm-21-1484). The authors have no conflicts of interest to declare.

Ethical Statement: The authors are accountable for all aspects of the work in ensuring that questions related to the accuracy or integrity of any part of the work are appropriately investigated and resolved. Due to the retrospective nature of this study, the current study was granted an exemption by the Institutional Ethics Committee of Peking University School and Hospital of Stomatology. All procedures performed in the study were in accordance with the Declaration of Helsinki (as revised in 2013). Individual consent for this retrospective analysis was waived.
Open Access Statement: This is an Open Access article distributed in accordance with the Creative Commons Attribution-NonCommercial-NoDerivs 4.0 International License (CC BY-NC-ND 4.0), which permits the noncommercial replication and distribution of the article with the strict proviso that no changes or edits are made and the original work is properly cited (including links to both the formal publication through the relevant DOI and the license). See: https://creativecommons.org/licenses/by-nc-nd/4.0/.

\section{References}

1. Salma RG, Al-Shammari FM, Al-Garni BA, et al. Operative time, blood loss, hemoglobin drop, blood transfusion, and hospital stay in orthognathic surgery. Oral Maxillofac Surg 2017;21:259-66.

2. Park SY, Seo KS, Karm MH. Perioperative red blood cell transfusion in orofacial surgery. J Dent Anesth Pain Med 2017;17:163-81.

3. Goubran H, Sheridan D, Radosevic J, et al. Transfusionrelated immunomodulation and cancer. Transfus Apher Sci 2017;56:336-40.

4. Taniguchi Y, Okura M. Prognostic significance of perioperative blood transfusion in oral cavity squamous cell carcinoma. Head Neck 2003;25:931-6.

5. Szakmany T, Dodd M, Dempsey GA, et al. The influence of allogenic blood transfusion in patients having free-flap primary surgery for oral and oropharyngeal squamous cell carcinoma. Br J Cancer 2006;94:647-53.

6. Lodders JN, Parmar S, Stienen NL, et al. Incidence and types of complications after ablative oral cancer surgery with primary microvascular free flap reconstruction. Med Oral Patol Oral Cir Bucal 2015;20:e744-50.

7. Carniol ET, Marchiano E, Brady JS, et al. Head and neck microvascular free flap reconstruction: An analysis of unplanned readmissions. Laryngoscope 2017;127:325-30.

8. Singbartl G, Held AL, Singbartl K. Ranking the effectiveness of autologous blood conservation measures through validated modeling of independent clinical data. Transfusion 2013;53:3060-79.

9. Rogers SN, Horisk K, Groom P, et al. Management of anaemia and blood in patients having neck dissections or free flaps for head and neck cancer. Br J Oral Maxillofac Surg 2019;57:543-9.

10. Kao HK, Chang KP, Ching WC, et al. Postoperative Morbidity and Mortality of Head and Neck Cancers in Patients With Liver Cirrhosis Undergoing Surgical Resection Followed by Microsurgical Free Tissue Transfer. 
Ann Surg Oncol 2010;17:536-43.

11. Chau JK, Harris JR, Seikaly HR. Transfusion as a Predictor of Recurrence and Survival in Head and Neck Cancer Surgery Patients. J Otolaryngol Head Neck Surg 2010;39:516-22.

12. Danan D, Smolkin ME, Varhegyi NE, et al. Impact of blood transfusions on patients with head and neck cancer undergoing free tissue transfer. Laryngoscope 2015;125:86-91.

13. Puram SV, Yarlagadda BB, Sethi R, et al. Transfusion in head and neck free flap patients: practice patterns and a comparative analysis by flap type. Otolaryngol Head Neck Surg 2015;152:449-57.

14. Perisanidis C, Dettke M, Papadogeorgakis N, et al. Transfusion of allogenic leukocyte-depleted packed red blood cells is associated with postoperative morbidity in patients undergoing oral and oropharyngeal cancer surgery. Oral Oncol 2012;48:372-8.

15. Loeffelbein DJ, Julinek A, Wolff KD, et al. Perioperative risk factors for postoperative pulmonary complications after major oral and maxillofacial surgery with microvascular reconstruction: A retrospective analysis of 648 cases. J Craniomaxillofac Surg 2016;44:952-7.

16. Carson JL, Guyatt G, Heddle NM, et al. Clinical Practice Guidelines From the AABB: red blood cell transfusion thresholds and storage. JAMA 2016;316:2025-35.

17. Wong CJ, Vandervoort MK, Vandervoort SL, et al. A

Cite this article as: Su JQ, Xie S, Cai ZG, Wang XY. Developing a predictive risk score for perioperative blood transfusion: a retrospective study in patients with oral and oropharyngeal squamous cell carcinoma undergoing free flap reconstruction surgery. Ann Transl Med 2021;9(10):854. doi: 10.21037/atm-21-1484 cluster-randomized controlled trial of a blood conservation algorithm in patients undergoing total hip joint arthroplasty. Transfusion 2007;47:832-41.

18. Tomeczkowski J, Stern S, Müller A, et al. Potential cost saving of Epoetin alfa in elective hip or knee surgery due to reduction in blood transfusions and their side effects: a discrete-event simulation model. PLoS One 2013;8:e72949.

19. Nath A, Pogrel MA. Preoperative autologous blood donation for oral and maxillofacial surgery: An analysis of 913 patients. J Oral Maxillofac Surg 2005;63:347-9.

20. Oh AY, Seo KS, Lee GE, et al. Effect of preoperative autologous blood donation on patients undergoing bimaxillary orthognathic surgery: A retrospective analysis. Int J Oral Maxillofac Surg 2016;45:486-9.

21. Parkin IR, Chiu GA, Schwarz PA, et al. Acute perioperative normovolaemic haemodilution in major maxillofacial surgery. Br J Oral Maxillofac Surg 2008;46:387-90.

22. Perisanidis C, Mittlböck M, Dettke M, et al. Identifying Risk Factors for Allogenic Blood Transfusion in Oral and Oropharyngeal Cancer Surgery With Free Flap Reconstruction. J Oral Maxillofac Surg 2013;71:798-804.

23. Abu-Ghanem S, Warshavsky A, Carmel NN et al. Predictive factors for perioperative blood transfusion in neck dissection. Laryngoscope 2016;126:851-7.

(English Language Editor: J. Teoh) 